\title{
Primer Congreso de la Sociedad Interamericana de Filosofia
}

\section{DISCURSO DE DON MARIO CIUDAD}

"Señores: El Presidente de la República, en cuya representación tengo el honor de hablar, se siente halagado porque se hayan reunido en Chile, las distinguidas personalidades que concurren al Primer Congreso de la Sociedad Interamericana de Filosofía. Enaltece a nuestro país, el hecho de que en Sao Paulo haya sido designado sede del torneo filosófico que inauguramos en esta solemne sesión.

Los señores delegados extranjeros, a quienes saludo cordialmente, tendrán oportunidad de conocernos, es decir, habrán de captar las modalidades de vida dentro de las cuales transcurre la existencia pública y privada de los chilenos. Podrán darse cuenta de la heterogeneidad de criterios y aptitudes que prevalecen en los análisis de los asuntos políticos. Encontrarán que también predominan esas diferencias en otros planos más profundos y definitivos, en aquellos que no están sujetos a las oscilaciones y fugacidades del instante. Me refiero a las convicciones íntimas, a esas creencias fundamentales de las cuales la filosofía no ha podido prescindir, no obstante los esfuerzos para convertirla en una ciencia estricta. Chile es el país de los desacuerdos, desde el punto de vista de las ideas. Está muy lejos de nosotros la homogeneidad que uniforma y pone camisa de fuerza al pensamiento. 
Todas estas legítimas antinomias, que de ninguna manera excluyen una convivencia progresista y respetable, prueban fehacientemente que la vida chilena se desarrolla bajo el signo de una auténtica y valiosa libertad. Es lo más elevado y noble que podemos ofrecer a nuestros ilustres visitantes. La filosofía, en tanto disciplina ceñida y lógica, necesita del libre examen para encontrar el camino de la verdad. Es imprescindible esa autonomía, que permite al investigador atenerse en forma absoluta y exclusiva a los datos del problema; es insubstituible la independencia que lo protege de las influencias extrañas a los intereses científicos. El Presidente Ibáñez ha cuidado con esmero este ambiente espiritual, que ha de ser propicio a la cxposición y discusión de las tesis que se presentarán en el Primer Congreso de la Sociedad Interamericana de Filosofía. Chile es conocido por los hermosos paisajes en que se despliega esplendorosa la naturaleza, pero estamos más orgullosos aún de este cielo azul de la libertad, que es obra y patrimonio de los hombres.

Los Congresos de Filosofía sólo se conciben dentro del espíritu de la modernidad. La forma socio-cultural propia del pensamiento antiguo fué, como es bien sabido, la escuela filosófica. Unicamente la imaginación creadora de un Rafael, pudo reunir en su célebre Escuela de Atenas a Pitágoras con Aristóteles, a Heráclito con Platón, a Sócrates con Epicuro, en una aproximación admirable en tanto composición pictórica, pero imposible desde todo punto de vista. En cambio, los cuadros sociales tal vez específicos del presente, estén constituídos por las sociedades y los Institutos de Filosofía. La labor de investigación que se realiza en estas entidades, es visible en las publicaciones y congresos, en los cuales la filosofía aparece con todas las vibraciones de un proceso viviente y formativo.

Las diferencias anotadas no están desprovistas de significación. Al contrario, a través de ambas modalidades se revelan tipos de reflexión filosófica también muy diverisos. Los congresos, las sociedades y los institutos de filosofía tienen que ver, más bien, con un pensamiento que se preocupa de resolver problemas y no de formular amplias y audaces concepciones del mundo. Las formas socio-culturales 
que ha tomado la filosofía en nuestra época, son particularmente favorables para la elaboración de un pensamiento que aspira a la rigurosidad característica de la ciencia. En cambio, la escuela filosófica tiene su centro no sólo en las doctrinas del filósofo, sino también en su poderosa personalidad. En los orígenes se vislumbra una novedosa y firme actitud vital, junto al propósito de extender el dominio de las ideas al campo de los intereses de la existencia humana. Es lo que seguramente busca el público que seguirá las vicisitudes de este Congreso, constituído por gente culta, pero no especializada en las disciplinas filosóficas. Esta faz encuentra expresión en lo que vagamente llamamos destino, orientaciones, finalidades, que son palabras cargadas más con un contenido afectivo que teórico.

Pero en la convocatoria de este Primer Congreso de la Sociedad Interamericana de Filosofía, los organizadores se preguntan: “¿qué puede esperar hoy el hombre de la filosofía en el campo de las ciencias naturales, culturales y lógicas, y en el orden de una orientación valorativa de su conducta?" Es decir, ya en los planteamientos iniciales mismos, se ha tenido el buen tino de conciliar ambas esferas, la de los intereses teóricos con estas necesidades espirituales íntimas. $\mathrm{Y}$ esto es importantísimo en la época presente y nuestro Hemisferio, todavía en un proceso de maduración.

En efecto, más que nunca es imperiosa una feliz alianza entre la razón y las situaciones humanas. Somos propensos a desarrollar un verdadero volcanismo anímico; la lógica del corazón, con sus poderosas impulsiones, a menudo perturba la lógica de la razón. Esta es impersonal, objetiva, y a través de ella es posible suscitar acuerdos y eliminar desavenencias. La razón es lo que hay de común en el género humano, y por intermedio de ella, como pensaba Malebranche, es posible establecer una comunidad entre las inteligencias. Sólo beneficios pueden provenir de utilizar la rigurosidad filosófica en el esclarecimiento de los problemas que dividen y alejan a los hombres. Estamos muy distantes del excesivo optimismo que atribuye a la reflexión serena un poder infinito. No creemos que alguna vez vayan a obtenerse resultados definitivos en la tarea de esfumar los 
motivos de divergencia. De todos modos, aquí está el camino a un examen tranquilo y seriamente conducido, sin violencias, de los asuntos que, por lo general, despiertan reacciones agudas y vehementes. Es posible que los acuerdos no se produzcan, pero al menos coincidiremos en respetarnos por esta común condición de seres dotados de inteligencia. Es el influjo que puede ejercer el uso de la razón en las situaciones humanas.

Las resonancias prácticas de la filosofía en la vida del hombre, sus repercusiones en la conducta colectiva a través de la cátedra universitaria y de la enseñanza en el liceo, así como el interés mismo de estas disciplinas, movieron al gobierno a patrocinar el presente congreso. Las consideraciones antes señaladas instaron al Presidente de la República a actuar en este sentido por intermedio del Ministerio de Educación Pública, de la Secretaría General de Gobierno y de la Superintendencia de Educación.

Empero, también se apreció en su exacto valor el siguiente hecho: uno de los temas que se tratarán en las sesiones plenarias, propone el estudio del "significado de la Filosofía en la cultura de América”. El filósofo no es un sujeto abstracto ni la filosofía un producto intemporal, pese al legítimo anhelo de llegar a verdades de perenne validez. La filosofía posee un tiempo histórico, se desarrolla dentro de determinados marcos culturales. En otras palabras, la adscripción de todos nuestros países al sistema espiritual en formación que denominamos la "Cultura de América", nos torna solidarios por participar en estructuras supranacionales, de carácter continental. América ha establecido conexiones estables y muy bien organizadas, que nos aproximan en el orden político, económico y aun social. Pero también existe, en virtud de un común fundamento cultural, la solidaridad de los espíritus, en este caso, la solidaridad en el ejercicio de la grande y noble tarea de pensar filosóficamente la realidad.

Posiblemente, podría atribuirse cierta etérea fragilidad a estos nexos que se concretan a través de la reflexión filosófica. Mas, hay que apartar dichas opiniones, que sólo pueden ser sostenidas por quienes son incapaces de pensar con finura. Un Congreso Interame- 
ricano de Filosofía es expresión genuina y valiosa de esta solidaridad de los espíritus. Por eso nadie que auténticamente sienta su pertenencia física y moral a América, puede quedar al margen de una iniciativa de tan elevadas proyecciones. Las arraigadas convicciones americanistas del Presidente de la República lo impulsaron, por eso mismo, a ver con simpatía una reunión de esta naturaleza. De allí que haya prestado la franca y entera colaboración de que tiene noticia directa la comisión organizadora.

Señores:

"En representación del Presidente Ibáñez saludo a los distinguidos delegados extranjeros que han tenido a bien concurrir al Primer Congreso de la Sociedad Interamericana de Filosofía. Asimismo soy portador de una palabra de estímulo y de aprobación a los profesores chilenos que toman parte en estas deliberaciones. El buen éxito y brillantes resultados coronarán; indudablemente, estos trabajos. Con esta actitud ejemplar de hombres que se reúnen a pensar juntos, ganará el pensamiento filosófico en América y se enriquecerá la convivencia interamericana con amistades firmes y perdurables".

\section{DISCURSO DEL SR. LEOPOLDO ZEA}

"Señor Ministro de Relaciones Exteriores, señor Secretario General de Gobierno, señor Rector de la Universidad de Chile, señores rectores, señores decanos, señores profesores, señores delegados al Primer Congreso de la Sociedad Interamericana de Filosofía, IV Interamericano; me ha correspondido el alto honor de hablar en nombre de los delegados hispanoamericanos. Honor que he aceptado por haber sido hecho, a través de mi persona, a México, mi país.

¿De qué otra manera empezar que no sea agradeciendo y destacando el enorme esfuerzo y sacrificio que significa la realización de este congreso? Realización llevada a cabo con una generosidad extraordinaria, especialmente dada la situación económica por la que atraviesa este gran país latinoamericano a semejanza de otros muchos en esta misma América. Generosidad que no es otra cosa que un signo de 
la permanente preocupación de Chile por las diversas expresiones de la cultura, aun por aquellas aparentemente más abstractas como la filosofía. En este sentido la República Chilena se encuentra a la altura de su gran herencia filosófica, si vamos a entender por filosofía alga más que la elaboración de sistemas metafísicos. Una filosofía moral, política y social sobre la cual las figuras más altas de la filosofía llamada universal, levantaron sus sistemas metafísicos. Filosofía moral, política y social que ha sido la expresión cotidiana del pensamiento o filosofía americanos. En este campo Chile ha aportado a la filosofía americana los nombres de un Francisco Bilbao, un José Victorino Lastarria y un Valentín Letelier. Nombres a los que hay que agregar los de figuras más actuales, con una preocupación más académica y didáctica, pero no menos interesada por los aspectos morales y sociales de América como Enrique Molina; o los miembros de la generación filosófica contemporánea formada por una pléyade de jóvenes chilenos, cuyos nombres sería largo enumerar, y a la cual se debe esta reunión.

Grupo de jóvenes filósofos que no han vacilado ante los obstáculos que implicaba la realización de este congreso. Obstáculos que han sido vencidos contando, como contó este grupo, con la ayuda abierta del gobierno y las autoridades universitarias chilenas. Grupo de filósofos que han formado la Sociedad Chilena de Filosofía que se ha encargado de la organización de este congreso.

Con el congreso que ahora se inaugura América da un paso más en los esfuerzos que se vienen realizando por una mayor comprensión entre nuestros diversos países a través de un diálogo, cada vez más amplio, de los estudiosos americanos de la filosofía, el pensamiento y las ideas. La reunión que ahora se inicia es una más de las que en los últimos años se han venido organizando en América como lo son las realizadas en Haití, los Estados Unidos y México, donde se efectuaron los tres primeros Congresos Interamericanos de Filosofía; así como los congresos celebrados en el Perú, en 1951, y en el Brasil, en 1954, al igual que la reunión celebrada en 1953 en La Habana, Cuba, para celebrar y recordar fechas importantes en la his- 
toria y formación cultural de estos países. Congresos y reuniones llevados a cabo, como el de ahora, sin fines de propaganda política circunstancial alguna; sin otra preocupación que la cultural que las mismas implican. Congresos y reuniones sin más meta que la comprensión a través del diálogo; el intercambio de las ideas; la demostración de que es posible hablar, discutir, dialogar, entender y comprender los puntos de vista de los otros sin renunciar necesariamente a los propios, ni exigir a aquéllos la renuncia de los suyos. Ahora, como ayer, nos encontramos con rostros conocidos; rostros de hombres cuyo modore pensar nos es cada vez más familiar. Los sabemos amigos y nos alegra tener la oportunidad de intercambiar con ellos nuestros puntos de vista sobre problemas y soluciones que también ellos se deben estar planteando. Comunicarles nuestros hallazgos y nuestras dudas. Pero también nos encontramos con otros rostros, los de otros hombres en los cuales adivinamos a nuevos amigos. Adivinamos la posibilidad de extendernos a sí mismos, de extender, esto es, acrecentar, nuestra humanidad a través de estos nuevos contactos, de esta nueva posibilidad de comprensión.

Dialogar, comprender, entendernos los unos con los otros, sin necesidad de renunciar a nuestros propios modos de ser, tal es, al final de cuentas, el fruto de estas reuniones. No se van a resolver los grandes problemas de la existencia del hombre, ni los que puedan implicar su relación con el absoluto. Simple y puramente un intercambio de las formas como estos problemas y estas relaciones se nos hacen patentes. ¿Justifica esto reuniones de esta naturaleza? Creo que sí, y con creces. En una época como la nuestra en que la incomprensión y la violencia va siendo la norma para las relaciones humanas; en una época en que predominan los odios raciales, de clase, políticos e ideológicos; en una época en que los intereses más mezquinos tratan de justificar su natural intransigencia apelando a ideas que son todo lo contrario de esta intransigencia, como las de Democracia, Libertad y Justicia; en una época como ésta, insisto, la reunión de hombres que no buscan sino la mayor comprensión de sus ideas, ofreciendo a cambio, comprensión para las que les pueden ser apa- 
rentemente ajenas, se encuentra plenamente justificada, como justificados son todos los esfuerzos que se hagan para su realización.

Desde este punto de vista estos congresos vienen a ser algo más que la reunión de un grupo de hombres que sólo se interesen por hablar y discutir sin meta alguna. La importancia de las mismas está en el espíritu que los anima. El mismo espíritu por el cual otros hombres, otros pensadores, otros ideólogos de la cultura en América, lucharon en el pasado. Ideólogos como los ya citados, Bilbao, Lastarria, Letelier y los de otros países hermanos como Sarmiento, Alberdi, Mora, González Prada, Montalvo, Martí y otros muchos más en la América Latina, que lucharon por que fuese posible en este continente la libertad de expresión, la independencia de pensamiento y el afán de comprensión, bases sobre las cuales tendrá que levantarse cualquier filosofía que sea auténtica filosofía. A partir de este punto de vista podemos afirmar que nuestra América ha ido adquiriendo suficiente madurez para entrar en un diálogo más amplio, de radio universal, como lo demuestra la presencia de destacados filósofos europeos y orientales en cada una de estas reuniones, o la participación de los filósofos americanos en los grandes congresos internacionales. Suposición de madurez que no tiene su origen en una autosugestión sino en el reconocimiento que para la misma van haciendo patentes hombres de cultura de otros países ajenos a los nuestros. Por ejemplo, la Sociedad Internacional de Sociedades de Filosofía, con sede en Europa ha hecho consultas en México sobre la posibilidad de que sea la América Latina la sede de uno de los Congresos Internacionales de Filosofía, el XIII. Esto es, nuestra América va adquiriendo ya suficiente rango en el diálogo filosófico para atraer la atención de otros pueblos que buscan, al igual que los nuestros, una mayor comprensión para sus ideas y doctrinas, en lugar de la brutal imposición de las mismas.

Así, en nombre de los delegados hispanoamericanos quiero hacer patente una vez más, nuestro agradecimiento al pueblo chileno en 
https://doi.org/10.29393/At371-525ATPC10525

56

Atenea

general, y a cada uno de los patrocinadores y organizadores en particular, por la nueva oportunidad que se nos brinda para entrar en renovado contacto con los representantes de la joven, pero pujante, filosofía chilena, así como con varios de los representantes de la filosofía europea, con nuestros colegas en los Estados Unidos y con todos nosotros entre sí. Pueden estar seguros los realizadores de este congreso de que no serán defraudados; que el espíritu que los alentó en su realización será mantenido. Espíritu que sólo puede mantenerse, en tierras como las de este país, en las cuales se respira la esencia de toda auténtica filosofía, la Libertad". 